\title{
Cognitive Coping and Frontal Lobe Epilepsy: A Task Switching Study
}

\section{Amara Gul* and Hira Ahmad}

Department of Applied Psychology, The Islamia University of Bahawalpur, Pakistan

\begin{abstract}
The present study examines the role of cognitive coping in task switching abilities of patients with frontal lobe epilepsy (FLE). Participants ( 25 patients with FLE \& 25 healthy controls) performed switching task and reported the use of cognitive coping strategies. Results showed that patients with FLE had sustained attention for emotion which lead to the unbalanced switch cost between tasks. This pattern of results did not appear in controls. Relative to controls, patients with FLE reported more frequent use of maladaptive cognitive coping strategies such as self-blame, other blame, rumination, and catastrophizing and less frequent use of putting into perspective, positive refocusing, positive reappraisal, acceptance and planning. Cognitive coping strategies were associated with switch costs. Greater use of maladaptive strategies was positively correlated with weaker task switching abilities. This study for the first time highlighted the role of cognitive coping in frontal lobe epilepsy during switching conditions. Implications of results were discussed.
\end{abstract}

Keywords: Frontal lobe epilepsy; Seizures; Emotion; Cognition; Task switching; Coping strategies; Rumination; Catstrophizing

\section{Introduction}

Frontal lobe epilepsy (FLE) is characterized by short-term, frequent seizures that arise in the frontal lobes of the brain [1]. Patients may experience abnormalities in body posturing, motor skills and sensorimotor tics. These symptoms are recurrent due to the overactivationwithinone central foci that moves to lateral brain regions [2]. Frontal lobe monitors a wide array of higher order cognitive functions $[3,4]$ such as learning, inhibitory control, reward processing and working memory [5,6]. Patients following frontal lobe damage show disorganization, failure in accomplishment of goal-directed activities and response inhibition [7-10]. Patients with frontal lesions have more perseverative and set loss errors as compared to patients with nonfrontal lesions [11]. Patients with frontal lesions in either hemisphere take longer time to learn the cognitive task and show more errors $[12,13]$. Frontal lobe lesions are associated with increased distractibility [14]. After excisions of the frontal lobe, patients show impairment in memory and learning specifically an inefficient use of a strategy which is required for successful performance [15-18]. Excisions from left or right frontal cortex results in severe learning impairments [19] because frontal cortex is critical for learning associative tasks and retrieval of the information from memory $[20,21]$. Patients demonstrate inability to plan, co-ordinate and organize the sequence of activities after damage to frontal lobe $[22,23]$. Lesions in frontal lobe causeinability to adopt new rules $[13,24,25]$ and increased time cost during task switching [26]. Patients with frontal lobe lesions experience significant problems in response preparation and inhibition [27].

Frontal lobes have compound connections to cortical, subcortical and brain stem sites and control higher order cognitions such as inhibition, cognitive flexibility, problem solving, planning, and behavior. Thus, executive function is broad term which encapsulates diverse anatomical structures diffused in central nervous system [28]. Prefrontal cortex play a fundamental role in cognitive development such as lateral areas are involved in higher executive functions which are required to perform goal-directed actions whereas ventromedial areas control emotional and instinctual behaviors [29]. Prefrontal cortex monitors executive control, emotion processing, working memory, learning and temporal structure of the task relevant response. This brain region is responsible for coordination and transfer of information that is required for operation of multiple level cognitions [30]. Dorsolateral prefrontal cortex is associated with set-shifting, planning, problem solving and response inhibition [31]. Anterior cingulate cortex is involved in decision making, inhibition of task irrelevant response, and motivated behaviors [32]. Orbitofrontal cortex is involved in set maintenance, impulse control and evaluation of subjective experiences of emotions [33].

In an article "An integrative theory of prefrontal cortex function" written by Miller and Cohen et al. [34] it is argued that prefrontal cortex is the primary control center for cognitions. The control is implemented by the increased gain of either sensory or motor neurons that are engaged by elements of the task or goal. Prefrontal cortex has supervisory role for the active maintenance of and achievement of task goals affecting visual processes and sensory modalities for emotional evaluation, memory, retrieval and response execution. As a net result, neural activity along pathways is established for cognitive mapping that is required to perform a given task. This theory draws concepts from the early view of selective visual attention [35] which is based on the competition between stimulus attributes. Brain selects stimulus attributes and gains increased neural response to those stimulus dimensions. These neural outputs have more access to reach downstream processing stage and as a result guide behavior. According to Miller and Cohen, selective attention is in fact control of attention. Prefrontal cortex controls the sensory input and the resultant neural response, as well as the organizations of memory and emotions. Control of cognitions involves prefrontal reciprocal connectivity with the sensory and motor cortices, and the limbic system. Thus, in situations of the receipt of biased signals, cognitive control is required to override the selective attention, error monitoring, decision-making and memory inhibitionand to promote the task-relevant responding.

The "cascade of control model" by Banich (2009) assumes the sequential flow of brain regions involved in the maintenance of attentional sets to achieve a certain goal. These regions are dorsolateral

*Corresponding author: Amara Gul, Assistant Professor, Department of Applied Psychology, The Islamia University of Bahwalpur, Pakistan, Tel: +92 (0) 307504 7077; E-mail: amara_psychology@hotmail.com

Received June 13, 2014; Accepted July 25, 2014; Published August 15, 2014

Citation: Gul A, Ahmad H, (2014) Cognitive Coping and Frontal Lobe Epilepsy: A Task Switching Study. Int J Neurorehabilitation 1: 112. doi:10.4172/2376-0281.1000112

Copyright: () 2014 Gul A, Ahmad H. This is an open-access article distributed under the terms of the Creative Commons Attribution License, which permits unrestricted use, distribution, and reproduction in any medium, provided the original author and source are credited. 
and the mid- prefrontal cortex, and the anterior dorsalcingulate cortex. The posterior dorsolateral prefrontal cortex maintains the appropriate attentional set and rules out biased and irrelevant information. The middorsolateral prefrontal cortex follows the task-relevant representation that is instrumental to achieve the goal. The posterior dorsal anterior cingulate cortex is responsible for task relevant response selection [36].

According to Miyake and Friedman's theory of executive functions, updating, inhibition and switching are three important interrelated aspects of executive functioning. Updating is the continuous monitoring and maintenance of the contents of working memory. Inhibition is the capacity to supersede a response which is not relevant in the given condition [37]. Switching is the cognitive flexibility to shift between different task-sets. Generally, switching experiments require participant to shift between two tasks, when each task is assigned a specific task-rule. For an efficient switching, the participants' attention must be in accordance with the task-rule $[38,39]$. A cost may arise due to the deferral in selection of the task-rule called as switch cost [40]. The switch cost is product of the activation of relevant task-rule in working memoryand inhibitory mechanisms to reduce theintrusion from competing task-set $[41,42]$. These functions are predominantly performed by areas in the prefrontal cortex [43]. Patients with FLE often report cognitive function deficits such as impaired attention, concentration and memory [44]. Patients with FLE show impaired setshifting performance on visuomotor sequencing task [45]. In situations which require dual-task performance, patients with FLE show failure in cognitive switching [46].

Neuropsychological studies demonstrate that patients with FLE have impaired performance on cognitive functionssuch as attention, memory, response inhibition, memory span, anticipatory behavior and concept formation $[47,48]$. Cognitive deficits are displayed in executive dysfunctions in response initiation, selection and inhibition $[49,50]$. Patients with FLE show deficits in set shifting and inhibition on colorword interference test [51]. Focal damage of the frontal cortex leads to increased switch costs [26].

Patients with epilepsy experience emotional distress during seizures that are accompanied by vigilant attention toward emotionrelated stimuli [52]. Patients with focal epileptic seizures display intense emotional agitation due to the decreased synchrony in signals recorded from neural network involved in emotional processing and a total loss of synchrony between amygdala and orbito-frontal cortex [53]. Cognitive coping is helpful to regulate emotions, thoughts and cognitions [54]. Failure in cognitive coping results in pathological behavior and psychiatric disorders [55]. Frequent use of coping strategies such as rumination, self-blame, catastrophizing results in emotional problems whereas positive reappraisal leads to less vulnerable behavior toward emotional turmoil [56-58]. Coping is defined as an individual's constant effort to manage demands of the internal and external environment which taxes resources of the person. It is a cognitive mechanism which helps to accomplish goal-directed and motivational behaviors [59]. Deficits in executive functions are associated with the activation of maladaptive coping strategies, whereas higher levels of executive functions are involved with the application of adaptive coping strategies and positive emotional as well as behavioral outcomes [60].

\section{The present study}

The present study aimed to examine the relationship between cognitive coping strategies and task switching in patients with FLE. To date, it is unclear how strategies for cognitive coping influence executive functions associated with frontal lobe epilepsy and whether patients with FLE employ any differential coping mechanism on cognitive level relative to healthy individuals. This study is the first investigation into coping strategies in patients with FLE in connection with their switching abilities.

\section{Hypotheses}

1. Contrary to controls, patients with FLE would show sustained attention for emotion rather than age task. This should result in larger switch cost for age task.

2. Patients with FLE would show higher use of maladaptive coping strategies than controls.

3. Switch costs would be related with coping strategies.

\section{Method}

\section{Participants}

Twenty five patients $(M=27.36, \mathrm{SD}=3.45,23-35$ years) with FLE took part in the study at Jinnah and Services Hospital, Lahore. Patients were diagnosed on the basis of EEG evidence and seizure semiology with onset in the frontal lobe. The average age at the onset of FLE was 17 years. All patients were on anticonvulsant medication and had dysfunction outside the frontal region as assessed by MRI. Patients had no history or current psychiatric disorder as assessed by clinical psychologist according to the guidelines of DSM-IV [61]. Twenty five healthy individuals $(M=25.80, \mathrm{SD}=5.17,23-35$ years $)$ were contacted from local community with an inclusion criteria of having no history or current symptoms of neurological or psychiatric disorder according to the guidelines of the DSM-IV [61] and no use ofanticonvulsant medication. Patients and controls were matched on demogrpahic variables: age, gender, education, economic status andintellectual function (as measured by Standard progressive matrices [62] (Table 1).

\section{Materials}

\section{Task switching experiment:}

Experimental stimuli: The experiment was designed with 48 facial photographs (24 faces of children with age range as 9-12 years and 24 faces of adults with age range as 18-24 years) which depicted happy and neutral expressions of emotions. Half of these faces portrayed female gender. Images were standardized on $288 \times 288$ pixels with white background. Prior to the final experimental testing, it was ensured that

\begin{tabular}{|l|l|l|}
\hline Characteristics & Patients $(\mathbf{n}=\mathbf{2 5})$ & Control $\mathbf{( n = 2 5 )}$ \\
\hline Gender & N & N \\
\hline Female & 10 & \\
\hline Male & 15 & 11 \\
\hline Economic Status & & 14 \\
\hline Lower & 02 & \\
\hline Middle & 15 & 03 \\
\hline Higher & 08 & 13 \\
\hline Education & & 09 \\
\hline Primary & - & \\
\hline Secondary & 10 & - \\
\hline Higher & 15 & 12 \\
\hline Intellectual Function & 25 & 13 \\
\hline Psychiatric Comorbidity & None & 25 \\
\hline
\end{tabular}

Table 1: Demographic and Clinical Characteristics for Patients with FLE and Healthy Controls 
the emotional expression in the pictures were recognizable by patients and controls. Ratings were obtained on a 10-point scale describing the salience of emotions in the pictures $(1=$ poor; $10=$ excellent $) .48$ pictures were selected from a large pool on the mean ratings (happy $M=8.00$, $\mathrm{SD}=0.50)$ of 20 subjects from each participant group with good interrater reliability (79).

Experimental design and display: The experiment was designed in E-prime software [63] with an alternating-run paradigm of task switching [39]. The tasks were emotion and age categorization to faces. Both tasks were counterbalanced across participants. The experiment was designed with 241 trials and was presented to the participants on laptop screen. The structure of trials was comprised of a fixation, blank screen followed by the presentation of facial image. The images were presented on coloured background screen which served as task cue. These images remained on the screen until response. Manual responses were recorded by pressing fixed keys on the keyboard, $1=$ child; $2=$ adult; happy $=3$; neutral $=4$. The faces were remained on the screen until the response was completed. The first trial in the task switching experiment had no task switch, therefore the analysiswere exclusive of the data on the first trial. Switch trial was defined as the trial with a changed task as it was on the previous trial whereas the repeat trial had the same task asthe previous trial. The analyses were performed on equal number of the switch and repeat trials ( $240=120$ switch; 120 repeat) with a clear distinction of emotion and age task ( 120 switch trials $=60$ emotion, 60 age; 120 repeat trials $=60$ emotion, 60 age). The structure and display of the trials are shown in Figure 1.

Cognitive Emotion Regulation Questionnaire (CERQ): Cognitive coping was measured through CERQ. It is a 36 item selfreport questionnaire, developed by Garnefskiand colleagues [64]. The questionnaire was used to examine strategiesthat a person employs in order to reduce the severity of negative life events. The CERQ has nine subscales which are conceptually different from each other: self-blame, other blame, rumination, catastrophizing, putting into perspective, positive refocusing, positive reappraisal, acceptance and planning. Each subscale has 4 -items and refers to a cognitive strategy used to regulate emotions. Self-blaming refers to blame on one self for the negative experiences in life; other-blame refers to putting blame on environment or another person; rumination refers to thinking about negative events;

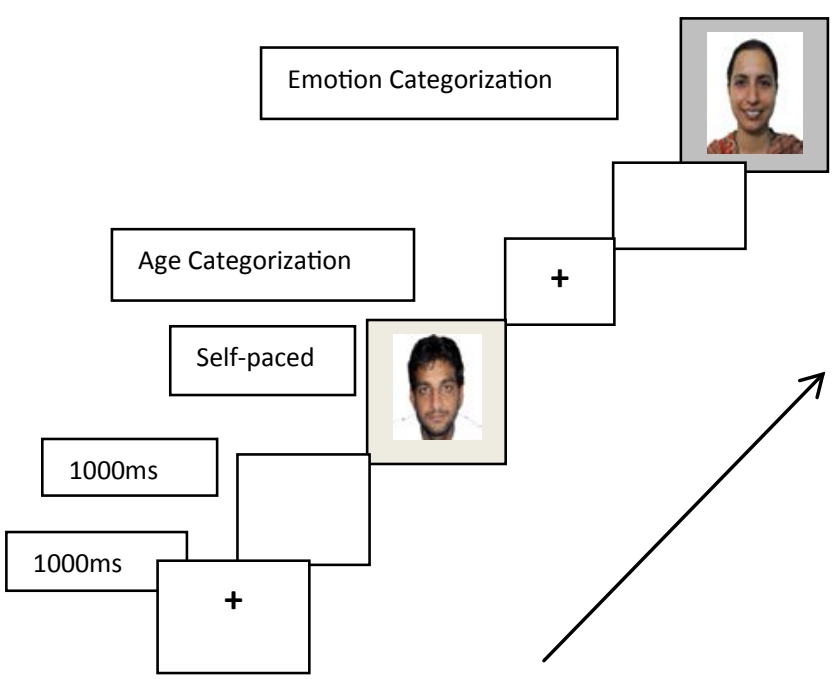

Figure 1: Example of the Stimuli and displays for the emotion and age task catastrophizing indicates thoughts emphasizing negative experiences; putting into perspective refers minimizing the seriousness of the event relative to other events; positive refocusing refers thinking about joyful issues; positive reappraisal refers to thoughts of creating positive meaning to life; acceptance refers to approval of the past experiences; planning refers to thoughts of practical steps to handle negative events. Each strategy is scoredon a 5-point Likert scale ranging from 1 (almost never) to 5 (almost always). Total score on each subscale ranges from 4 to 20 . Subscales have good internal consistencies ranging from 0.68 to $0.86[65,66]$.

\section{Results}

\section{Task switching}

Response times (reaction times: RTs) for the first trial (no switch trial) and those exceeding 2.5 standard deviations from each participants' mean were excluded. Switch costs for each task were calculated by subtracting mean RTs on repeat trials from mean RTs on switch trials). Mean RTs were submitted to a repeated measures analysis of variance with trial (switch: task is changed as the previous trial vs. repeat: task is same as the previous trial), task (emotion vs. age) as within subject factors and group (patients with FLE vs. controls) as between subject factors.

The main effect of trial was significant $F(1,48)=111.00, p<0.001$, $\eta p 2=.69$, switch $(M=1319.00 \mathrm{~ms})$; repeat $(M=957.41 \mathrm{~ms})$. Main effects of task $F(1,48)=3.40, p=.07, \eta p 2=.06$, (emotion $M=1121.23$; age $M=$ $1155.16 \mathrm{~ms})$ and group $F(1,48)=5.48, \mathrm{p}=.02, \eta \mathrm{p} 2=.10$, patients with FLE $(M=1351.00)$; control $(M=925.42 \mathrm{~ms})$ were not significant. These was a significant interaction between trial $\mathrm{x}$ task $F(1,48)=13.10, p<0.001$, $\eta p 2=.21$, switch (emotion $M=1284.00$; age $M=1354.15 \mathrm{~ms}$ ) repeat (emotion $M=959.00$; age $M=956.16 \mathrm{~ms}$ ). The interaction between trial $\mathrm{x}$ group was not significant $F(1,48)=.04, p=.84, \eta p 2=.00$, patients with FLE (switch $M=1535.20 \mathrm{~ms}$; repeat $M=1167.00 \mathrm{~ms}$ ); controls (switch $M=1103.00 \mathrm{~ms}$; repeat $M=748.10 \mathrm{~ms}$ ). The interaction between trial $\mathrm{x}$ task $\mathrm{x}$ group was significant $F(1,48)=26.35, p<0.001, \eta p 2=.35$, Figure 2 . This higher order interaction was analyzed through separate repeated measures analysis of variance for patients and controls. For patients, there was a significant main effect of trial $F(1,24)=51.51$, $p<0.001, \eta p 2=.68$, switch $(M=1535.20 \mathrm{~ms})$; repeat $(M=1167.00 \mathrm{~ms})$ and task $F(1,24)=6.67, p<0.01, \eta p 2=.21$, emotion $(M=1308.60 \mathrm{~ms})$; age $(M=1393.33 \mathrm{~ms})$. There was a significant interaction between trial $\mathrm{x}$ task $F(1,48)=50.52, p<0.001, \eta p 2=.67$. Switch cost for the age task was larger than the emotion task $t(24)=7.10, p<0.001$, emotion $(M=280.38$ $\mathrm{ms})$; age $(\mathrm{M}=456.55 \mathrm{~ms})$. For controls, there was a significant main effect of trial $F(1,24)=60.35, p<0.001, \eta p 2=.71$, switch $(M=1103.00$ $\mathrm{ms})$; repeat $(M=748.10 \mathrm{~ms})$. The effect of task was not significant $F(1$, 24) $=1.02, p=.32, \eta p 2=.04$, emotion $(M=933.66 \mathrm{~ms})$; repeat $(M=917.00$ $\mathrm{ms})$. The interaction between trial $\mathrm{x}$ task was not significant $F(1,24)$ $=0.92, p=.34 \eta p 2=.03$. Errors are shown in Table 2 .

\section{Coping strategies and task switching}

Pairwise comparison between scores on subscales for CERQ showed that patients with FLE and controls use different coping strategies. Pearson correlations were carried out to determine the relationship between switch costs and scores on coping strategies. Results showed significant correlations between scores on coping strategies and switch costs. Self-blaming $(r=.43, p<0.001)$, other-blaming $(r=.44, p<0.001)$, rumination $(r=.46, p<0.001)$, and catastrophizing $(r=.47, p<0.001)$ had a positive contribution towards switch costs. In contrast, planning $(r=-$ $.31, p<0.05)$ and acceptance $(r=-.27, p<0.05)$ had negative association 




Figure 2: Mean reaction times (ms) for switch and repeat trials

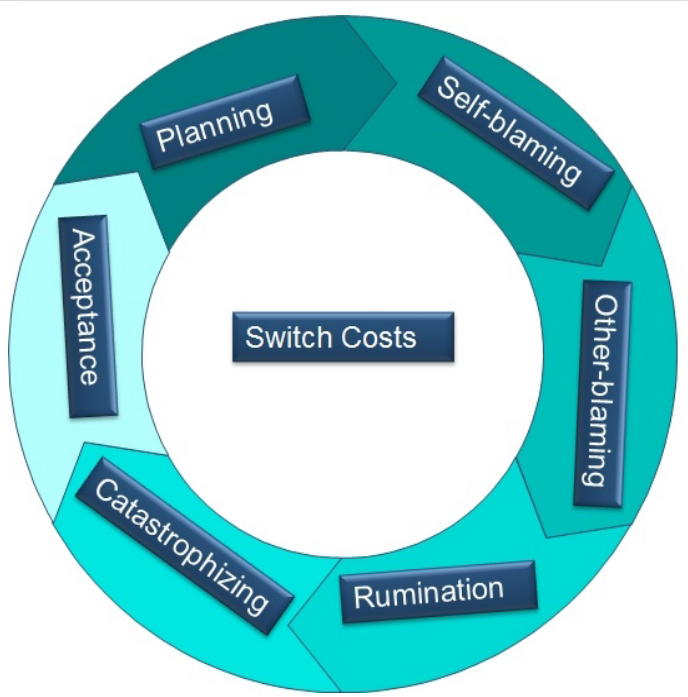

Figure 3: The schematic diagram for the coping mechanism is portrayed

\begin{tabular}{|l|l|l|l|}
\hline & Patients & Controls & \\
\hline & $\boldsymbol{M}(\mathbf{S D})$ & $\boldsymbol{M}$ (SD) & \\
\hline Self-blaming & $14.12(3.43)$ & $5.72(1.27)$ & $t(24)=13.22, p<0.001$ \\
\hline Other-blaming & $13.60(3.57)$ & $5.56(1.52)$ & $t(24)=12.19, p<0.001$ \\
\hline Rumination & $14.16(4.10)$ & $6.24(1.23)$ & $t(24)=10.25, p<0.001$ \\
\hline Catastrophizing & $14.80(4.71)$ & $5.36(1.38)$ & $t(24)=10.40, p<0.001$ \\
\hline Positive refocusing & $7.48(2.32)$ & $16.20(2.39)$ & $t(24)=19.48, p<0.001$ \\
\hline Positive reappraisal & $8.00(2.19)$ & $16.24(2.53)$ & $t(24)=15.06, p<0.001$ \\
\hline Acceptance & $6.92(1.91)$ & $15.96(2.74)$ & $t(24)=13.71, p<0.001$ \\
\hline Planning & $6.56(2.02)$ & $15.60(2.53)$ & $t(24)=15.39, p<0.001$ \\
\hline Putting into perspective & $6.88(1.96)$ & $17.16(2.39)$ & $t(24)=16.10, p<0.001$ \\
\hline Cognitive coping & $93.08(11.72)$ & $104.04(9.94)$ & $t(24)=3.92, p<0.001$ \\
\hline
\end{tabular}

Table 2: Scores on Subscales of CERQ for Patients and Controls

with switch costs. Few strategies such as positive refocusing ( $r=-.23$, $\mathrm{p}=.11)$, positive reappraisal $(r=-.23, \mathrm{p}=.11)$ and putting into picture $(r=-.02, \mathrm{p}=.86)$ had no significant relationship with switch costs.

\section{Discussion}

The present study was designed with to examine three main objectives (1) switch costs in patients with FLE and healthy individuals (2) cognitive coping strategies in patients with FLE (3) relationship between switch costs and coping strategies. Results supported first hypothesis of the study. Switch costs for the age task was larger than the emotion task. This effect was not evident in controls. This result is consistent with previous studies suggesting the role of frontal lobe in executive functions $[22,23]$. Damage in frontal lobe results in deficient goal-directed activities, response inhibition and organization [7-10,1114]. Lesions in frontal lobe leads to impaired memory, learning [1519] and retrieval from memory [20,21]. These abnormalities cause incapacity to adopt task-rule when the task switches [13,24-26]. The epileptic seizures in focal areas are associated with weak set-shifting ability [45]. Alongside, there are deficits in broad cognitive domains of attention, memory, and response selection [44,47-50] observed in interference tasks [51]. Patients with epilepsy experience heightened emotional behavior and attention to emotion-related stimuli [52] due to an abnormal synchrony predominant in amygdala and orbitofrontal cortex [53]. Our results showed that patients with FLE had sustained attention to emotion which delayed the performance of age task. On comparison, a larger switch cost was observed for age task. These patterns of results were in contradiction with the controls data. Healthy controls paid equal attention to both tasks, thus no asymmetric switch costs appeared for the tasks.

The second hypothesis of the study was supported by the finding that patients with FLE had weaker cognitive coping and maladaptive coping strategies relative to controls. Contrary to controls, patients with FLE reported a greater use of self-blame, other blame, rumination, and catastrophizing whereas a lesser use of strategies as putting into perspective, positive refocusing, positive reappraisal, acceptance and planning. The frequent use of rumination, self-blame, and catastrophizing play a positive role in emotional disorders. Positive reappraisal is associated with less frequent emotional chaos [56-58]. The switch costs were positively associated with self-blame, otherblame, rumination and catastrophizing. This result supported the third hypothesis of the study and depicted that higher use of self-blame, other-blame, rumination and catastrophizing were associated with task switching deficits. Cognitive coping strategies such as putting into perspective, positive refocusing, positive reappraisal, and acceptance and planning had an inverse relationship with switch costs. Higher use of these strategies was related with lesser switch costs. Notably, correlations werenot significant for positive refocusing, positive reappraisal and putting into perspective.This result showed that blaming oneself or others for negative life experiences occupies mind and slows down the flow of cognitions. Previous research depicted that blaming is associated with poor recovery from traumatic experiences [67], however, our results clarified the basic mechanism of reduced rehabilitation. The self or other blaming interrupts the cognitive stream, as a result cognitions get stagnant.Another contributing factor towards cognitive decline is rumination about negative life events. The present finding gained support from the previous finding that catastrophic thinking is associated with difficulty in disengaging attention from negative experiences.

In contrast to these maladaptive strategies, acceptance and planning play influential role in efficient cognitive functioning. Approval of the past experiences, no matter negative in valence and problem solving approach help in reducing switching deficits. Acceptance and commitment are new behavioral and cognitive approaches to desensitize the negative life experiences [68]. The schematic diagram for the coping mechanism is portrayed in Figure 3. Therapists should consider modification of the negative schema that is activated in patients with FLE that would be extremely beneficial for effective rehabilitation. 
Citation: Gul A, Ahmad H, (2014) Cognitive Coping and Frontal Lobe Epilepsy: A Task Switching Study. Int J Neurorehabilitation 1: 112. doi: $10.4172 / 2376-0281.1000112$

\section{Limitations and Future Directions}

This study for the first time demonstrated that cognitive coping is an important mechanism for task switching abilities in patients with FLE. Strategies for cognitive coping can serve as an indicator of the cognitive decline associated with frontal lobe epilepsy. These results are important for therapeutic interventions in frontal lobe epilepsy. It can help guide the cognitive therapists to focus on the structure of coping mechanism and adapt therapeutic process to modify maladaptive cognitive strategies. Such adaptations could aid the process of neurorehabilitation and provide support for patients with cognitive deficits. However, results of the present study are constrained due to the small sample size; therefore the study must be replicated with larger sample. Future research must also focus whether switching deficits associated with FLE can be improved with therapeutic interventions. It might be of practical value to examine neural correlates of coping strategies to prevent relapse in patients with epileptic seizures.

\section{References}

1. Haut S (2014) "Frontal Lobe Epilepsy". eMedicine Neurology.

2. "Frontal lobe seizures: Symptoms". Diseases and Conditions. Mayoclinic.com. Retrieved 2009-10-17.

3. Shallice T (1982) Specific impairments of planning. Philos Trans R Soc Lond B Biol Sci 298: 199-209.

4. Fuster JM (1989) The prefrontal cortex. 2nd ed. New York: Raven. Press.

5. Colzato LS, Pratt J, Hommel B (2012) Estrogen modulates inhibition of return in healthy human females. Neuropsychologia 50: 98-103.

6. Jacobs E, D'Esposito M (2011) Estrogen shapes dopamine-dependent cognitive processes: implications for women's health. J Neurosci 31: 52865293.

7. Luria AR (1966) Higher cortical functions in man. London: Tavistock.

8. Duncan J (1986) Disorganization of behavior after frontal lobe damage. Cogn Neuropsychol 3: 271-290.

9. Schwartz MF, Reed ES, Montgomery M, Palmer C, Mayer NH (1991) The quantitative description of action disorganization after braindamage: a case study. Cogn Neuropsychol 8: 381-414.

10. Perret $E$ (1974) The left frontal lobe of man and the suppression of habitual responses in verbal categorical behaviour. Neuropsychologia 12: 323-330.

11. Stuss DT, Levine B, Alexander MP, Hong J, Palumbo C (2000) Wisconsin card sorting test performance in patients with focal frontal and posterior brain damage: effects of lesion location and test structure on separable cognitive processes. Neuropsychologia 28: 388-402

12. Drewe EA (1975) Go - no go learning after frontal lobe lesions in humans. Cortex 11: 8-16.

13. Drewe EA (1974) The effect of type and area of brain lesion on Wisconsin card sorting test performance. Cortex 10: 159-170.

14. Burgess PW, Shallice T (1996) Response suppression, initiation and strategy use following frontal lobe lesions. Neuropsychologia 34: 263-272.

15. Owen AM, Sahakian BJ, Semple J, Polkey CE, Robbins TW (1995) Visuospatial short-term recognition memory and learning after temporal lobe excisions, frontal lobe excisions or amygdalo-hippocampectomy in man. Neuropsychologia 33: 1-24.

16. Owen AM, Morris RG, Sahakian BJ, Polkey CE, Robbins TW (1996) Double dissociations of memory and executive functions in working memory tasks following frontal lobe excisions, temporal lobe excisions or amygdalohippocampectomy in man. Brain $119: 1597-1615$.

17. Owen AM, Doyon J, Petrides M, Evans AC (1996) Planning and spatial working memory: a positron emission tomography study in humans. Eur $\mathrm{J}$ Neurosci 8: 353-364.

18. Owen AM, Evans AC, Petrides M (1996) Evidence for a two-stage modelof spatial working memory processing within the lateral frontalcortex: a positron emission tomography study. Cereb Cortex 6: 31-38.
19. Petrides M (1985) Deficits on conditional associative-learning tasks after frontal- and temporal-lobe lesions in man. Neuropsychologia 23: 601-614.

20. Petrides M, Alivisatos B, Evans AC, Meyer E (1993) Dissociation of human middorsolateral from posterior dorsolateral frontal cortex in memory processing Proc Natl Acad Sci U S A 90: 873-877.

21. Petrides M, Alivisatos B, Evans AC (1995) Functional activation of the human ventrolateral frontal cortex during mnemonic retrieval of verbal information. Proc Natl Acad Sci U S A 92: 5803-5807.

22. Shallice $T$ (1988) From neuropsychology to mental structure Cambridge:Cambridge University Press.

23. Knight RT (1984) Decreased response to novel stimuli after prefrontal lesions in man. Electroencephalogr Clin Neurophysiol 59: 9-20.

24. Milner B (1963) Effects of different brain lesions on card sorting. Arch Neuro 9: $100-110$.

25. Robinson AL, Heaton RK, Lehman RA, Stilson DW (1980) The utility ofthe Wisconsin Card Sorting Test in detecting and localizing frontallobe lesions. J Consult Clin Psychol 48: 605-614.

26. Rogers RD, Sahakian BJ, Hodges JR, Polkey CE, Kennard C, et al. (1998) Dissociating executive mechanisms of task control following frontal lobe damage and Parkinson's disease. Brain 121 : 815-842.

27. Verfaellie M, Heilman KM (1987) Response preparation and response inhibition after lesions of the medial frontal lobe. Arch Neurol 44: 1265-1271.

28. Alvarez JA, Emory E (2006) Executive function and the frontal lobes: a metaanalytic review. Neuropsychol Rev 16: 17-42.

29. Fuster JM (2002) Frontal lobe and cognitive development. J Neurocytol 31 : 373-385.

30. Beleza P, Pinho J (2011) Frontal lobe epilepsy. J Clin Neurosci 18: 593-600. doi:10.1016/j.jocn.2010.08.018.

31. Clark L, Bechara A, Damasio H, Aitken MR, Sahakian BJ, et al. (2008) Differential effects of insular and ventromedial prefrontal cortex lesions on risky decision-making. Brain 131: 1311-1322.

32. Allman JM, Hakeem A, Erwin JM, Nimchinsky E, Hof P (2001) The anterior cingulate cortex. The evolution of an interface between emotion and cognition. Ann N Y Acad Sci 935: 107-117.

33. Rolls ET, Grabenhorst F (2008) The orbitofrontal cortex and beyond: from affect to decision-making. Prog Neurobiol 86: 216-244.

34. Miller EK, Cohen JD (2001) An integrative theory of prefrontal cortex function. Annu Rev Neurosci 24: 167-202.

35. Desimone R, Duncan J (1995) Neural mechanisms of selective visual attention. Annu Rev Neurosci 18: 193-222.

36. Banich MT (2009) "Executive function: The search for an integrated account". CurrentDirections in Psychological Science 18: 89-94. doi:10.1111/j.1467 8721.2009.01615.x

37. Miyake A, Friedman NP, Emerson MJ, Witzki AH, Howerter A, et al. (2000) The unity and diversity of executive functions and their contributions to complex "Frontal Lobe" tasks: a latent variable analysis. Cogn Psychol 41: 49-100.

38. Meiran N (2000) Reconfiguration of stimulus task-sets and response tasksets during task-switching. In S. Monsell\& J. Driver (Eds.), Control of cognitive processes: Attention and Performance XVIII (pp.377-399). Cambridge: MIT Press.

39. Rogers RD, MonsellS (1995) Costs of a predictable switch between simple cognitive tasks. Journal of Experimental Psychology: General 124: 207-231.

40. Mayr U, Kliegl R (2000) Task-set switching and long-term memory retrieval. J Exp Psychol Learn Mem Cogn 26: 1124-1140.

41. Rubinstein JS, Meyer DE, Evans JE (2001) Executive control of cognitive processes in task switching. J Exp Psychol Hum Percept Perform 27: 763-797.

42. Brass M, von Cramon DY (2002) Fractionating the neural substrate of cognitive control processes. Proceedings of the national academy of sciences, 99 14595-14600.

43. Aron AR, Monsell S, Sahakian BJ, Robbins TW (2004) A componential analysis of task-switching deficits associated with lesions of left and right frontal cortex. Brain 127: 1561-1573. 
Citation: Gul A, Ahmad H, (2014) Cognitive Coping and Frontal Lobe Epilepsy: A Task Switching Study. Int J Neurorehabilitation 1: 112. doi: $10.4172 / 2376-0281.1000112$

44. Shulman MB (2000) The Frontal Lobes, Epilepsy, and Behavior. Epilepsy Behav 1: 384-395.

45. McDonald CR, Delis DC, Norman MA, Tecoma ES, Iragui-Madoz VJ (2005) Is impairment in set-shifting specific to frontal-lobe dysfunction? Evidence from patients with frontal-lobe or temporal-lobe epilepsy. Journal of the International Neuropsychological Society 11: 477-481. http://dx.doi.org/10.1017/ S1355617705050484.

46. McDonald CR, Delis DC, Norman MA, Tecoma ES, Iragui VJ (2005) Discriminating patients with frontal-lobe epilepsy and temporal-lobe epilepsy: utility of a multilevel design fluency test. Neuropsychology 19: 806-813.

47. Exner C, Boucsein K, Lange C, Winter H, Weniger G, et al. (2002) Neuropsychological performance in frontal lobe epilepsy. Seizure 11: 20-32.

48. Helmstaedter C, Kemper B, Elger CE (1996) Neuropsychological aspects of frontal lobe epilepsy. Neuropsychologia 34: 399-406.

49. Helmstaedter C (2001) Behavioral Aspects of Frontal Lobe Epilepsy. Epilepsy Behav 2: 384-395.

50. Patrikelis P, Angelakis E, Gatzonis S (2009) Neurocognitive and behavioral functioning in frontal lobe epilepsy: a review. Epilepsy Behav 14: 19-26.

51. McDonald CR, Delis DC, Norman MA, Wetter SR, Tecoma ES, et al. (2005) Response inhibition and set shifting in patients with frontal lobe epilepsy or temporal lobe epilepsy. Epilepsy Behav 7: 438-446.

52. Lanteaume L, Bartolomei F, Bastien-Toniazzo M (2009) How do cognition emotion, and epileptogenesis meet? A study of emotional cognitive bias in temporal lobe epilepsy. Epilepsy Behav 15: 218-224.

53. Bartolomei F, Trébuchon A, Gavaret M, Régis J, Wendling F, et al. (2005) Acute alteration of emotional behaviour in epileptic seizures is related to transient desynchrony in emotion-regulation networks. Clin Neurophysiol 116 2473-2479.

54. Garnefski N, Kraaij V, Spinhoven, PH (2001) Negative life events, cognitive emotion regulation and depression. Personality and Individual Differences 30 : 1311-1327.

55. Garnefski N, Kraaij V (2006) Relationships between cognitive emotion regulation strategies and depressive symptoms: A comparative study of five specific samples. Personality and Individual Differences 2006; 40:1659-1669.
56. Garnefski N, van den Kommer T, Kraaij V, Teerds J, Legerstee J (2002) The relationship between cognitive emotion regulation strategies and emotional problems. European Journal of Personality 2002; 16,403-420.

57. Garnefski N, Teerds J, Kraaij V, Legerstee J, Van den Kommer T (2004 Cognitive emotion regulation strategies and depressive symptoms: differences between males and females. Personality and Individual Differences 36: 267276 .

58. Kraaij V, Garnefski N, de Wilde E J, Dijkstra A, Gebhardt W (2003) Negative life events and depressive symptoms in late adolescence: bonding and cognitive coping as vulnerability factors? Journal of Youth and Adolescence 32: 185-193.

59. Stroebe MS, Folkman S, Hansson RO, Schut H (2006) The prediction of bereavement outcome: development of an integrative risk factor framework. Soc Sci Med 63: 2440-2451.

60. Campbell LK, Scaduto M, Van Slyke D, Niarhos F, Whitlock JA, et al. (2009) Executive function, coping, and behavior in survivors of childhood acute lymphocytic leukemia. J Pediatr Psychol 34: 317-327.

61. American Psychiatric Association. Diagnostic and Statistical Manual of Menta Disorders. (4thedn). American Psychiatric Association, Washington, DC; 1994.

62. Ravens JC (1938) Guide to using Progressive Matrices. London: The Director of Psychological Research.

63. Schneider W, EschmanA, Zuccolotto A (2002) Prime user's guide. Pittsburgh, PA: Psychology Software Tools, Inc.

64. Garnefski N, Kraaij V, Spinhoven P (2002) Manual for the use of the Cognitive Emotion Regulation Questionnaire. Leiderdorp, The Netherlands: DATEC.

65. Garnefski N, Kraaij V, Spinhoven P (2001) Negative life events, cognitive emotion regulation and depression. Personalityand Individual Differences 30 1311-1327.

66. Garnefski N, Kraaij V (2007) The Cognitive Emotion Regulation Questionnaire Psychometric Features and Prospective Relationships with Depression and Anxiety in Adults. European Journal of Psychological Assessment 23: 141-149.

67. Startup M, Makgekgenene L, Webster R (2007) The role of self-blame for trauma as assessed by the Posttraumatic Cognitions Inventory (PTCl): a selfprotective cognition? Behav Res Ther 45: 395-403.

68. Hayes SC (2004) Acceptance and commitment therapy, relational frame theory, and the third wave of behavioral and cognitive therapies. Behavior therapy 35: 639-665. 